\title{
PERILAKU HIDUP BERSIH DAN SEHAT DENGAN PENDEKATAN PARTISIPATIF KELAS VII DI MTSN 2 KOTA TANGERANG
}

\author{
Lela Kania, Sarifah Tsamaniah Mabruroh \\ Sekolah Tinggi Ilmu Kesehatan Kharisma Persada \\ Tangerang Selatan, 15417, Indonesia \\ E-mail: lelakania@masda.ac.id
}

\begin{abstract}
ABSTRAK
Berdasarkan Riskesdas (2013) provinsi Banten rumah tangga perilaku hidup bersih dan sehat (PHBS) dengan kriteria baik menurut kabupaten/kota di Provinsi Banten. Secara umum proporsi rumah tangga dengan PHBS baik di Provisi Banten adalah 34,2\% termasuk Kota Tangerang adalah PHBS baik (34,5\%). Akan tetapi dalam Rencana Strategi Kementrian Kesehatan (2015) Perilaku Hidup Bersih dan Sehat memiliki target sebesar (80\%). Merupakan penelitian quasi experimen dengan tujuan untuk mengidentifikasi perbedaan antara variabel independen dengan dependen, data yg dikumpulkan dengan cara kuesioner. Jumlah sampel sebanyak 60 siswa di MTSN 2 Kota Tangerang dibagi menjadi dua kelompok yaitu kelompok eksperimen dan kelompok kontrol. Dari hasil penelitian Hasil uji statistik diperoleh nilai p-value sebesar 0,000 dapat disimpulkan bahwa ada perbedan sebelum dan sesudah perilaku hidup bersih dan sehat dengan pendekatan partisipatif kelas VII di MTSN 2 Kota Tangerang dan untuk nilai posttest pada kelompok kontrol dan kelompok eksperimen memiliki nilai p-value sebesar 0.004 dapat disimpulkan bahwa ada perbedaan sesudah kelompok kontrol dan seseudah eksperimen pengetehuan dengan pendekatan partisipatif kelas VII di MTSN 2 Kota Tangerang sedangkan pada kelompok eksperimen $p$-value sebesar 0,022 dapat disimpulkan bahwa ada perbedaan sebelum dan sesudah perilaku hidup bersih dan sehat dengan pendekatan partisipatif kelas VII di MTSN 2 Kota Tangerang dan nilai postest $p$-value kelompok eksperimen $p$-value sebesar 0,03. Dari hasil penelitian ini diharapkan penelitian ini dapat dilanjutkan dengan tingkat Sekolah Menengah Akhir atau Madrasah Aliyah agar dapat mengetahui pengetahuan dan perilaku hidup bersih dan sehat.
\end{abstract}

Kata kunci : : Pengetahuan, Perilaku Hidup Bersih dan Sehat

\begin{abstract}
ABSTRACK
Based on the Riskesdas (2013) Banten province households have clean and healthy behavior (PHBS) with good criteria according to regencies / cities in Banten Province. In general, the proportion of households with PHBS both in Banten Provision was 34.2\% including Kota Tangerang, which was good PHBS (34.5\%). However, in the Strategic Plan of the Ministry of Health (2015) Clean and Healthy Life Behavior has a target of (80\%). It is a quasi-experimental study with the aim of identifying differences between independent variables and dependent data collected by questionnaire. The total sample of 60 students in MTSN 2 Tangerang City was divided into two groups, namely the experimental group and the control group. From the results of the study, the statistical test results obtained p-value of 0,000 can be concluded that there are differences before and after clean and healthy lifestyle with participant class VII approach in MTSN 2 Tangerang City and for the posttest value in the control group and experimental group has a p-value the value of 0.004 can be concluded that there is a difference after the control group and an experimental experiment with participatory class VII approach in Tangerang City MTSN 2 while in the experimental group p-value is 0.022 can be concluded that there are differences before and after clean and healthy behavior with a participatory approach class VII in MTSN 2 Tangerang City and the experimental group p-value post-test pvalue of 0.03. From the results of this study it is expected that this research can be continued with the level of Middle School or Madrasah Aliyah in order to find out the knowledge and behavior of clean and healthy life.
\end{abstract}

Keywords $\quad$ : knowledge, clean and healthy lifestyle 


\section{PENDAHULUAN}

Anak-anak pada usia sekolah merupakan periode yang sangat menentukan kualitas manusia pada masa dewasa. Pada periode anak, banyak permasalahan kesehatan yang diidetifikasi sangat menentukan kualitas anak dikemudian hari. Berbagai kesehatan tersebut antara lain meliputi kesehatan umum, gangguan perkembangan, gangguan perilaku dan gangguan belajar. Permasalahan kesehatan yang ditemukan tersebut pada umumnya akan menghambat pencapaian presentase pada peserta di sekolah.

Peserta didik usia sekolah merupakan awal dari masa depan bangsa. Dalam tujuan pembangunan nasional, peserta didik usia sekolah merupakan harapan untuk meningkatkan sumber daya manusia yang lebih baik agar dapat memajukan bangsa dan sekolah sebagai tempat belajar yang ideal mewujudkan cita-cita tersebut. Mengingat akan pentingnya peserta didik usia sekolah sebagai awal dari masa depan bangsa yang lebih baik, maka perlu ditanamkannya sikap dan perilaku yang baik pada peserta didik (Faozy, 2017).

Tujuan utama dari diajarkannya pendidikan kesehatan di sekolah yaitu sadarnya peserta didik dalam menerapkan Perilaku Hidup Bersih dan Sehat (PHBS).
Hal ini penting diperhatikan karena keberhasilan dari pendidikan kesehatan bukan pada banyaknya pengetahuan tentang kesehatan yang dimiliki peserta didik, tetapi pada kebiasaan hidup bersih dan sehat yang dilaksanakan dalam kehidupan sehari-hari. Penerapan PHBS yang dilaksanakan kan pada lima tatanan yaitu rumah tangga, sekolah, tempat umum, institusi kesehatan dan tempat kerja. Melaksanakan PHBS bermanfaat untuk mencegah, menanggulangi dan melindungi diri dari ancaman penyakit serta memanfaatkan pelayanan kesehatan yang bermutu efektif dan efisien.

Saat ini, masih terdapat perbedaan kriteria dalam menentukan usia anak. Undang-Undang No. 20 Tahun 2002 tentang Perlindungan Anak menyatakan bahwa yang dimaksud dengan anak-anak adalah individu yang belum berusia 18 tahun dan yang belum menikah. Namun, America Acedemic of Pediatric memberikan batasan usia anak yang mencakup mulai dari janin sampai mencapai usia 21 tahun. Batas usia anak tersebut ditentukan berdasarkan tingkat pertumbuhan fisik dan psikososial, tingkat perkembangan anak, dan karakteristik kesehatan mereka. Dengan demikian, anak usia sekolah mencakup pra sekolah, usia sekolah, remaja, awal usia dewasa 
hingga mencapai tahap proses perkembangan kedewasaan yang lengkap. Pada setiap tahap selalu ditemukan karakter yang khas pada aspek perilaku dan psikososiobudayanya. Meskipun demikian hingga kini program kesehatan di Indonesia belum memberikan perhatian yang memadai pada kesehatan anak, terutama pada anak-anak usia sekolah.

Pembangunan pendidikan di Indonesia telah memperlihatkan tingkat keberhasilan yang besar. Wajib belajar enam tahun, yang didukung oleh pembangunan infrakstruktur sekolah dan lanjut wajib belajar Sembilan tahun adalah program sector pendidikan yang diakui berhasil secara luas. Pada tahun akademik 2007/2008, jumlah murid SD di Indonesia (26.627.427 jiwa), memperlihatkan kecenderungan yang meningkat dari pada tahun 2006/2007 (26.278.236 jiwa). Namun, dibalik keberhasilan program pendidikan tersebut, terdapat berbagai fenomena yang teidak berlalu menggembirakan. Kasus tinggal kelas, terlambat masuk sekolah menengah pertama dan tidak mampu melanjutkan sekolah ke jenjang yang lebih tinggi merupakan masalah yang menjadi sorotan didunia pendidikan. Statistik pendidikan 2009 menunjukan dari lebih 26 juta anak SMP hanya sekitar
2.355.179 jiwa anak SMP yang melanjutkan ke SMA $(37,2 \%)$

Padahal usia, SMP dan SMA merupakan masa remaja yang menghadapi problematika yang jauh lebih kompleks daripada anak SD. Dengan demikian, perlu diketahui tingkat pengetahuan dan praktek perilaku hidup bersih dan sehat anak SMP. Perilaku hidup bersih dan sehat adalah obyek yang dipilih, sebab dinilai selaras dengan pembersihan diri, disamping cocok dengan tingkat perkembangan 12-15 tahun. Penelitian ini juga mengamati di sekolah MTSN 2 Kota Tangerang yang masih belum menjalankan program perilaku hidup bersih dan sehat, kerena masih ada beberapa tempat yang masih jauh dari bersih, contohnya siswa tidak mencuci tangan sebelum dan sesudah makan, siswa kurang aktivitas fisik dan membuang sampah di lantai dan dikantin. Dengan latar belakang diatas peneliti tertarik untuk melakukan penelitian mengenai "Perilaku Hidup Bersih Dan Sehat dengan Pendekatan Partisipatif kelas VII di MTSN 2 Kota Tangerang”.

\section{METODE}

Penelitian ini merupakan penelitian kuantitatif, dengan menggunakan metode penyuluhan 
kesehatan dengan rancangan quasi experiment dengan desain Non-equivalent Control Group Design with pre test dan post test design. Sampel pada penelitian ini adalah siswa MTSN 2 Kota Tangerang sebanyak 60 siswa terbagi menjadi kelompok eksperimen dan kelompok kontrol. Sampel diambil menggunakan teknik purposive sampling. Instrumen digunakan kuesioner pretes dan posttest. Analisis data dilakukan secara univariat dan bivariat menggunakan Uji T-Test untuk mengetahui pengaruh penyuluhan kesehatan melalui pendekatan partisipatif.

\section{HASIL}

1. Analisis univariat

Analisis univariat berisi hasil distribusi frekuensi responden berdasarkan hasil pretest dan posttest yang disajikan dalam tabel sebagai berikut :

Tabel 1. Hasil Rerata Skor

Pengetahuan PHBS

\begin{tabular}{ccc}
\hline \multirow{2}{*}{ Kelompok } & \multicolumn{2}{c}{ Rata-rata } \\
\cline { 2 - 3 } & Pretest & posttest \\
Ekperimen & 50,97 & 54,00 \\
Kontrol & 54,23 & 54,20 \\
\hline
\end{tabular}

Dari hasil penelitian pada variabel pengetahuan PHBS terhadap 30 responden yang diteliti dari kelompok eksperimen, didapatkan rerata skor prestest sebanyak 50,97. Pada posttest sebanyak 30 responden didapatkan nilai rerata skore 27,70 . Pada kelompok kontrol didapatkan hasil penelitian pada variabel pengetahuan PHBS terhadap 30 responden yang diteliti, nilai rerata pretest 54,23. Pada posttest 54,20. Pada posttest ekperimen dilakukannya penyuluhan PHBS kelas VII.

Tabel 2. Hasil Rerata Skor Perilaku Hidup Bersih dan Sehat

\begin{tabular}{ccc}
\hline \multirow{2}{*}{ Kelompok } & \multicolumn{2}{c}{ Rata-rata } \\
\cline { 2 - 3 } & Pretest & posttest \\
Ekperimen & 41,10 & 43,70 \\
Kontrol & 41,87 & 41,46 \\
\hline
\end{tabular}

Dari hasil penelitian pada variabel Perilaku Hidup Bersih dan Sehat terhadap 30 responden yang diteliti dari kelompok eksperimen, didapatkan rerata skor prestest sebanyak 41,10. Pada posttest sebanyak 30 responden didapatkan nilai rerata skore 43,70. Pada kelompok kontrol didapatkan hasil penelitian pada variabel Perilaku Hidup Bersih dan Sehat terhadap 30 responden yang diteliti, nilai rerata pretest 41,87. Pada posttest 41,46. 
Pada posttest ekperimen pengaruh dari dilakukannya dilakukannya penyuluhan PHBS penyuluhan terhadap perubahan kelas VII. pengetahuan dan perilaku hidup

2. Analisis bivariat bersih dan sehat kelas VII di MTSN 2

Analisis bivariat dilakukan untuk mengetahui ada atau tidaknya Kota Tangerang. Hasil dari bivariat dapat dilihat sebagai berikut:

Tabel 3. Hasil perbedaan pengetahuan tentang Perilaku Hidup Bersih dan Sehat

\begin{tabular}{ccccc}
\hline Kelompok & Pengetahuan PHBS & N & Mean & $p$-value \\
\hline \multirow{2}{*}{ Eksperimen } & Pretest & 30 & 50,97 & 0,001 \\
& Posttest & & 54,00 & \\
\multirow{2}{*}{ Kontrol } & Pretest & 30 & 54,23 & 0,965 \\
& Posttest & & 54,20 & \\
\hline
\end{tabular}

Tabel 4. Hasil Perbedaan Perilaku Hidup Bersih dan Sehat

\begin{tabular}{ccccc}
\hline Kelompok & $\begin{array}{c}\text { Perilaku Hidup } \\
\text { Bersih dan } \\
\text { Sehat }\end{array}$ & N & Mean & p-value \\
\hline \multirow{2}{*}{ Eksperimen } & Pretest & 30 & 50,97 & 0,000 \\
& Posttest & & 54,00 & \\
& Pretest & 30 & 54,23 & 0,450 \\
\hline
\end{tabular}

\section{DISKUSI}

Berdasarkan hasil uji statistik $U j i T$ test pada tabel 3, kelompok eksperimen terdapat ada perbedaan yang signifikan antara pengetahuan perilaku hidup bersih dan sehat sebelum dan sesudah yang diberikan penyuluhan dengan pendekatan partisipatif $(p=0,001)$. Penelitian ini sejalan oleh Dwi Arifiani Nur Khamidah dengan $p$-value sebesar 0,001 sehingga dapat disimpulkan bahwa ada peningkatan pengetahuan PHBS pada kelompok yang mendapatkan intervesi atau perlakuan berupa penyuluhan.

Hasil uji statistik pada kelompok kontrol menunjukan tidak ada perbedaan signifikasi antara sebelum dan sesudah tanpa dilakukan penyuluhuan $(p=0,965)$. 
Penelitian ini sejalan oleh Nur Annisa Alviana Dewi dengan p-value sebesar 0,492 sehingga dapat disimpulkan bahwa tidak ada pengaruh ceramah pendidikan kesehatan terhadap pengetahuan anakanak panti tentang PHBS.

Berdasarkan hasil uji statistik $U j i T$ test pada tabel 4, kelompok eksperimen terdapat ada perbedaan yang signifikan antara pengetahuan perilaku hidup bersih dan sehat sebelum dan sesudah yang diberikan penyuluhan dengan pendekatan partisipatif $(p=0,001)$. Penelitian ini sejalan oleh oleh Tri Krianto meningkatnya perilaku murid kisaran $30 \%-240 \%$.

Hasil uji statistik pada kelompok kontrol menunjukan tidak ada perbedaan signifikasi antara sebelum dan sesudah tanpa dilakukan penyuluhuan $(p=0,450)$. Penelitian ini sejalan oleh Nur Annisa Alviana Dewi dengan p-value sebesar 0,492 sehingga dapat disimpulkan bahwa tidak ada pengaruh ceramah pendidikan kesehatan terhadap pengetahuan anakanak panti tentang PHBS.

\section{SIMPULAN}

Simpulan yang diperoleh dari penelitian ini yaitu terindetifikasi pada kelompok kontrol kelas VII di MTSN 2 Kota tangerang mendapatkan nilai p-value sebesar 0,965 maka tidak ada perbedaan sebelum dan sesudah pengetahuan pada kelompok kontrol dengan pendekatan partisipatif kelas VII di MTSN 2 Kota Tangerang, sedangkan pada pengetahuan kelompok eksperimen mendapatkan hasil bahwa nilai $p$-value sebesar 0,000 dapat disimpulkan bahwa ada perbedan sebelum dan sesudah perilaku hidup bersih dan sehat dengan pendekatan partisipatif kelas VII di MTSN 2 Kota Tangerang.

Pada perilaku hidup bersih dan sehat, terindetifikasi pada kelompok kontrol mendapatkan nilai $p$-value sebesar 0,450 dapat disimpulkan bahwa tidak ada perbedaan sebelum dan sesudah perilaku hidup bersih dan sehat dengan pendekatan partisipatif kelas VII di MTSN 2 Kota Tangerang, sedangkan pada kelompok eksperimen $p$-value sebesar 0,000 dapat disimpulkan bahwa ada perbedaan sebelum dan sesudah perilaku hidup bersih dan sehat dengan pendekatan partisipatif kelas VII di MTSN 2 Kota Tangerang

\section{DAFTAR PUSTAKA}

Adisasmito, Wawan. 2010 .Teori dan Pengukuran Pengetahuan, Sikap dan Perilaku Manusia.Yogyakarta : Nuha Medika. 
Departemen Kesehatan RI. 2012. Perilaku Hidup Bersih dan Sehat. Bakti Husada.

Khamidah, Dwi Arifiani Nur. 2011. Perbedaan peningkatan pengetahuan tentang perilaku hidup bersih dan sehat (PHBS) antara metode permainan monopoli dan ceramah pada siswa SDN kebandingan kecamata kedungbanteng kabupaten tegal tahun 2010/2011. Skripsi

Evayanti, Ni luh Putu. 2012. Persepsi Siswa SMP Dalam Penerapan PHBS Tatanan Sekolah di Kelurahan Tugu dan Pasir Gunung Selatan Kota Depok. Tesis FIK UI.

Ervina Windasari. 2015. Fasilitas dan Pelaksanaan Perilaku Hidup Bersih dan Sehat (PHBS) pada Murid Sekolah Dasar yang Mempunyai dan Tidak Mempunyai Usaha Kesehatan Sekolah (UKS) di Kelurahan Jadirejo Kecamatan Sukajadi Kota Pekanbaru. Skripsi. Universitas Sumatera Utara. Faozy, Irchan. 2017. Perilaku Hidup Bersih dan Sehat Siswa Kelas VII SMP Negeri 1 Bumijaya Kabupaten Tegal Tahun Ajaran
2017. Skripsi. Universitas Negeri Yogyakarta.

Krinato, Tri. 2009. Perilaku Hidup Bersih dan Sehat dengan Pendekatan Partisipatif. Jurnal Kesehatan Masyaraka Nasional Vol.3.

Kementrian Pendidikan dan Kebudayaan Universitas Sebelas Maret Falkutas Kedokteran. 2013.Perilaku Hidup Bersih dan Sehat. Surakarta.

Muliadi, Irma Sari, 2015. Pengetahuan, Sikap, Perilaku Hidup Bersih dan Sehat Pada Mahasiswa FKIK UIN Syarif Hidayatullah Jakarta tahun 2015. Skripsi.

Notoatmodjo S. 2010 . Promosi Kesehatan Teori dan Aplikasi. Jakarta: PT Rineka Cipta.

Notoatmodjo S. 2012. Promosi Kesehatan dan Perilaku Kesehatan. Jakarta: PT Rineka Cipta.

Riset Kesehatan Dasar. 2013. Badan Penelitian Dan Pengembangan Kesehatan. Kementerian Kesehatan Republik Indonesia. Rogers 2005. The Desire to Learn. Ikip Singaraja 
Sugiyono. 2009. Metode penelitian

kuantitatif, kualitatif dan $R \& D$.

Bandung. Alfabeta.

Undang-Undang Republik Indonesia

Nomor 36 Tahun 2009 tentang

Kesehatan. Presiden Republik

Indonesia. 